\title{
Reduction the Effects of the Vibration Parameter on the Replacement Knee Joint during Daily Gait Cycle
}

\author{
Jumaa Salman Chiad Noor Dhia Yaseen \\ College of Engineering Biomedical Eng. Dep. \\ Al-Nahrain University, Baghdad, IRAQ \\ Firas Mohammed Abdul Ghani \\ College of Medicine \\ jumaachiad@yahoo.com noord 93@yahoo.com firasabdulghani75@yahoo.com
}

Received: 27-May-2018

Revised: 29-July-2018

Accepted: 18-Sep.-2018

http://doi.org/10.29194/NJES.21040486

\begin{abstract}
There are many patients who face a lot of things that hurt the knee joint. Knee replacement is the best solution to these problems. This research was based on reducing the vibrations of daily activities as measured by the frequency of foot and knee for the patient for three cases when the bare foot, sports shoes with ground air and sports shoes with ground air with silicon damping. Patient information for this work was of age, weight, height and leg length 48 years, $90 \mathrm{~kg}, 160 \mathrm{~cm}, 84$ $\mathrm{cm}$, respectively. The results was shown that the decline in acceleration results was in the case of sport shoes with ground air with silicon damping with $22.57 \%$, while the decline in vibration results was in the case of sports shoes with ground air with $-54.9 \%$.
\end{abstract}

Keywords: Knee Replacement, Vibration, Sport Shoes, Foot, Acceleration.

Introduction 1

The goal of the study was to analyze and minimize the effects of vibration on the replacement knee joint alternative to the patient during daily activities such as walking, sitting, standing and running. A series of mechanical and biomedical tests were performed to measure vibration data, various techniques were used to reduce the effects of vibration.

Total Knee replacement is also termed as knee anthroplasty. A surgical method of replacing the load bearing surfaces present in the knee joint so as to cure the pain bearing regions and disability areas of the joint such as osteoarthritis, ligament tearing, cartilage defects and meniscus tearing [1], as shown in Figure (1) [2].
There are three main component of total knee replacement:

The tibial component consists of a high-density polyethylene spacer fixed either to a metal tibial tray or to an interchangeable modular insert.

The femoral component is a metallic component with rounded surfaces mimicking the normal femoral condylar contours.

The patellar component is usually made up of high density polyethylene but can also be metal backed. [3]

\subsection{Gait cycle}

The gait cycle is defined as the period from heel contact of one foot to the next heel contact of the same foot. This cycle consists of two parts, stance and swing phase. On average, the gait cycle is about one second in duration with $60 \%$ in stance and $40 \%$ in swing. It has eight sub-phases which assist in determining overall coordination of the limbs, and assessing functional tasks associated with walking [4], as shown in figure (2) [5].

1.2 Vibration on the replacement knee joint

Knee joint vibration signals are obtained using an accelerometer placed at the mid patella position of the knee. These signals are also referred to as VibroArthrographic (VAG) signals. These signals can be used to design a computer-aided diagnosis system for non-invasive detection of knee joint disorders. Knee joint vibroarthrographic (VAG) signals acquired from extensive movements of the knee joints provide insight about the current pathological condition of the knee. VAG signals are non-stationary, aperiodic and non-linear in nature [6]. 


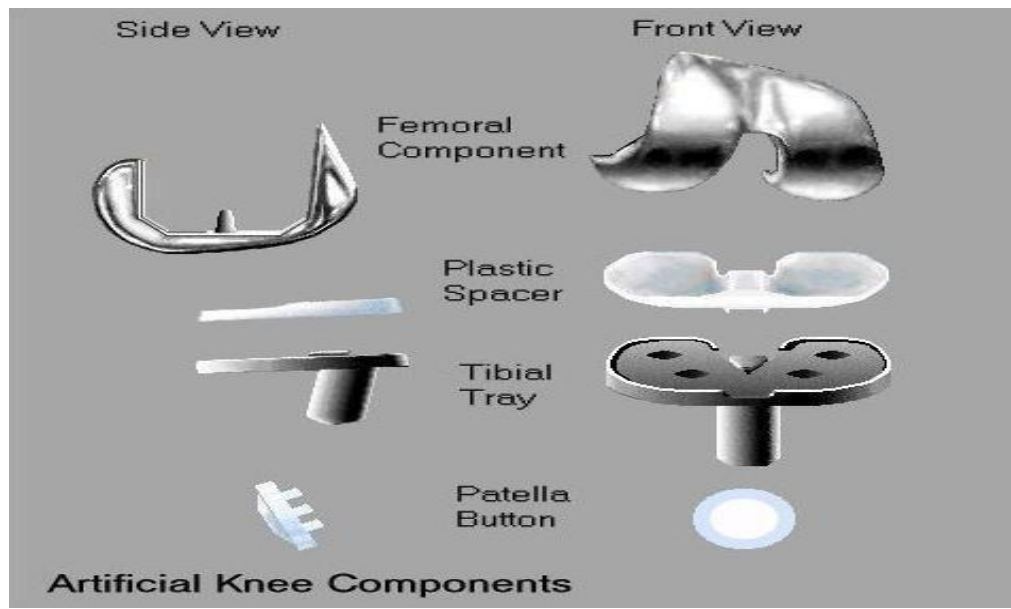

Figure 1: Total knee replacement component [2].

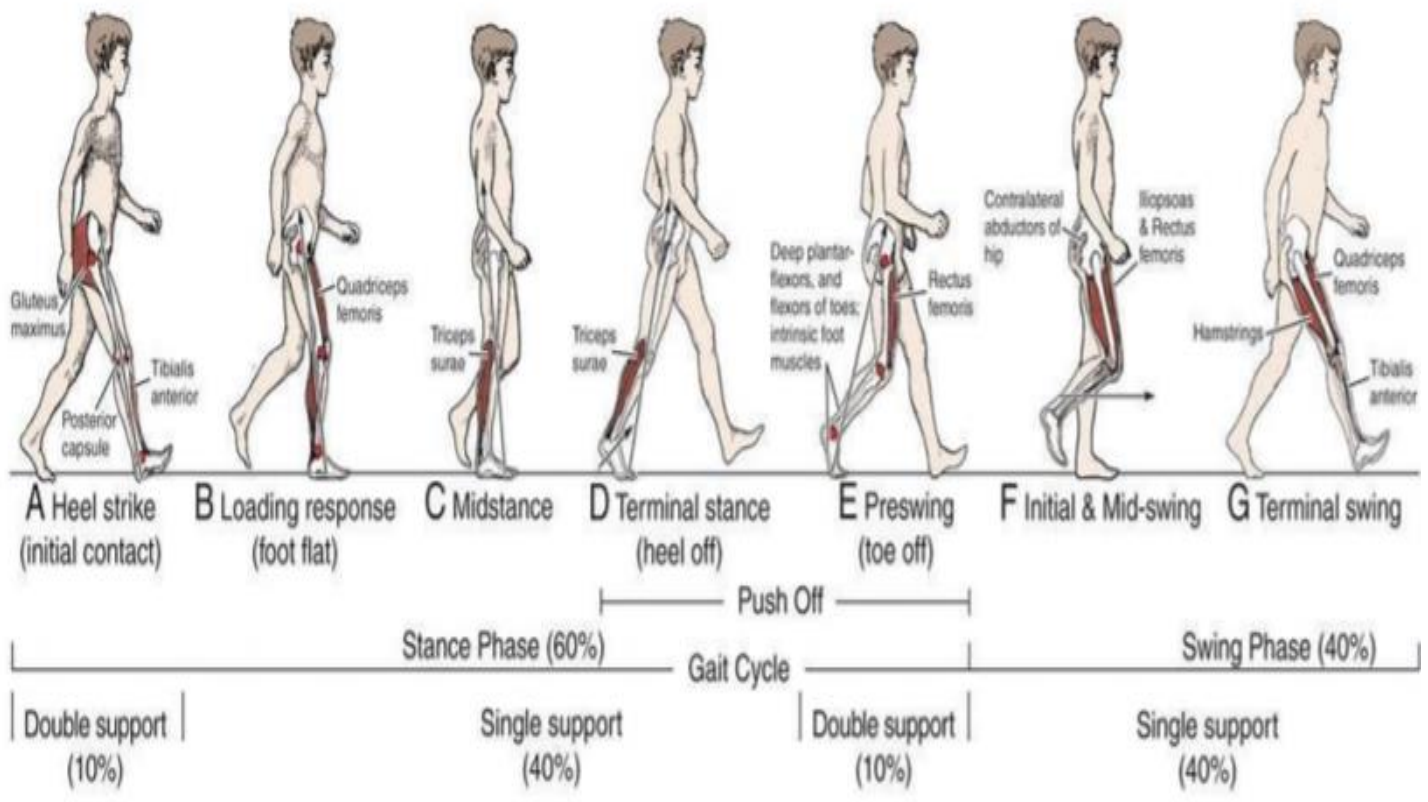

Figure 2: Phases of gait cycle [5].

\section{Experimental Procedure}

The objective of the research was to measure the vibration and acceleration of a patient with total knee replacement by use accelerometer sensor that was fixed on the foot and knee position of the patient leg by using different damping shoes such as without damping, sports shoes with ground air and sports shoes with ground air with silicon damping during gait cycle, the results that obtained from the accelerometer sensor were the acceleration results while the vibration results were obtained by convert the acceleration results in to the EXCEL program and used the Fourier transform in excel and got the vibration figures and results as shown in Figure (3), Figure (4), Figure (5), Figure (6), Figure(7), and Figure (8).

The patient was female and was of age, weight, length and leg length of 48 years, $90 \mathrm{Kg}, 160 \mathrm{~cm}$ and $84 \mathrm{~cm}$ respectively. The results are then transferred to the computer using a device nor axon U.S.A. Inc. • 13430 N. Scottsdale Rd., Suite 104 • Scottsdale, AZ 85254. Through it results were calculated.

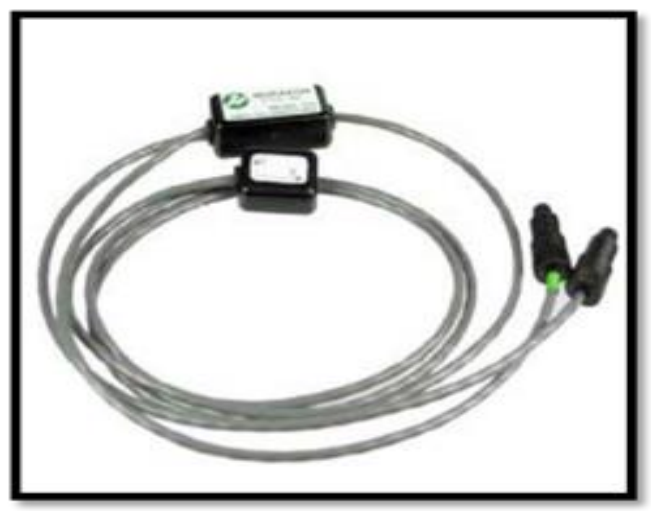

Figure 3: Accelerometer sensor. 


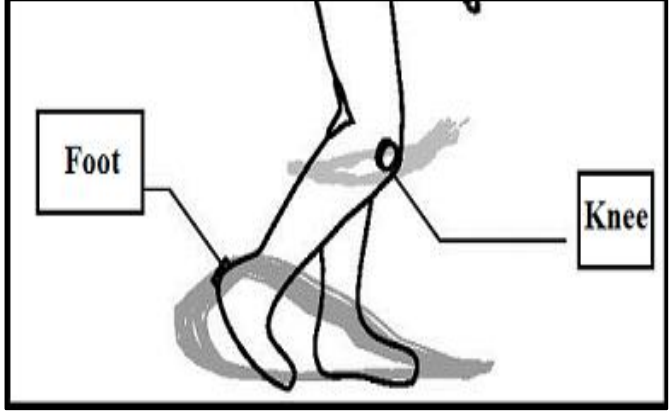

Figure 4: Accelerometer sensor position on the patient leg.

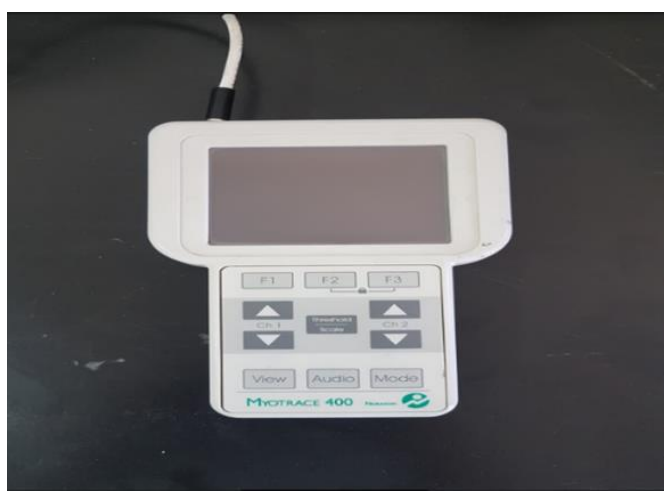

Figure 5: Noraxon electromyography device.

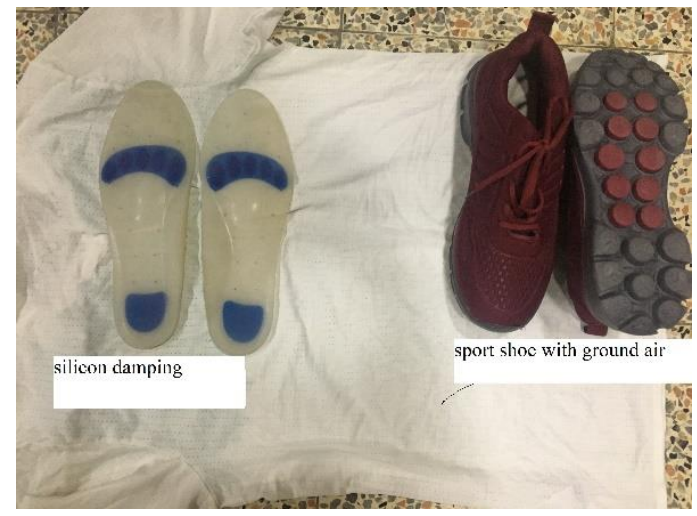

Figure 5: Damping shoes

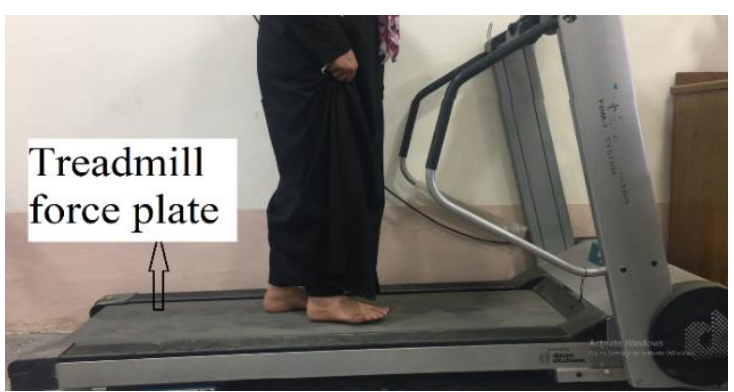

Figure 6: patient without shoe on the treadmill force plate with accelerometer sensor

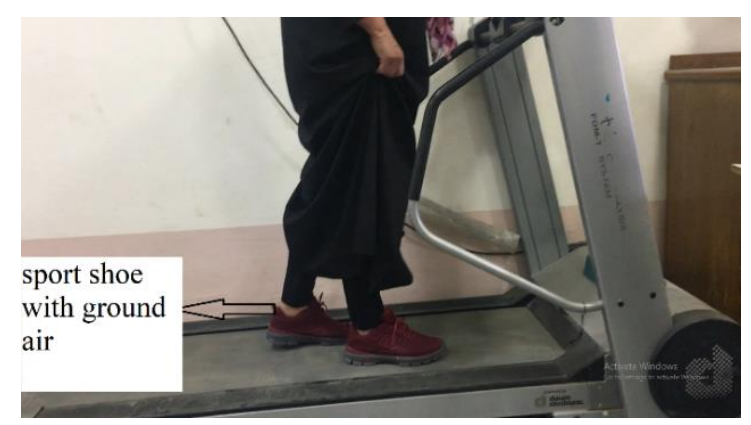

Figure 7: patient with sport shoe with ground air on the treadmill force plate with accelerometer sensor

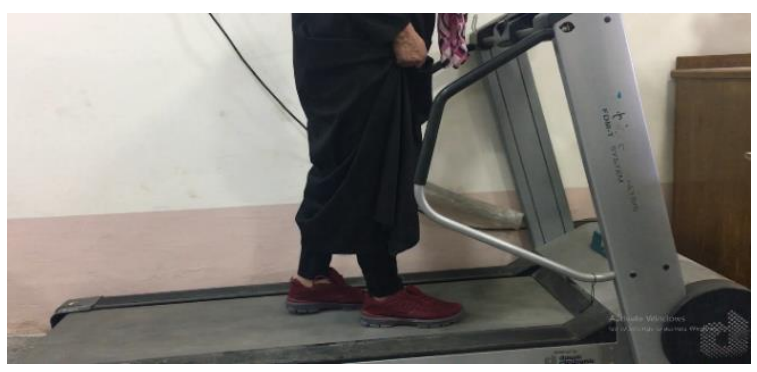

Figure 8: patient with sport shoe with ground air with silicon damping inside it on the treadmill force plate with accelerometer sensor

\section{Results and discussion}

Figure (9), Figure (10), Figure (11), Figure (12), Figure (13), and Figure (14) show the acceleration data for foot and knee joints respectively when using different type of damping foot. These results are rearranging in Table (1) and Table (2) which show that the level of acceleration at ankle joint is higher than knee joint this due to the fact that the foot is the first part faced the ground impact during gait cycle .These results exhibit the maximum acceleration in foot is recorded when using Athletic shoes with ground

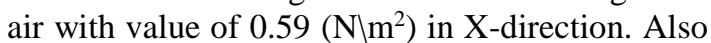
the maximum acceleration in knee joint is recorded when using Athletic shoes with ground air with value of $0.19\left(\mathrm{~N} \backslash \mathrm{m}^{2}\right)$ in Y-direction. Also results display that the maximum reduction in acceleration is recorded when using Athletic shoes with ground air with silicon damping with percent of $22 \%$. The percentage of reduction was obtained by used the equation:

((bare foot - the case of sport shoe with ground air with and without silicon damping)/ (bare foot)) $* 100 \%$ 


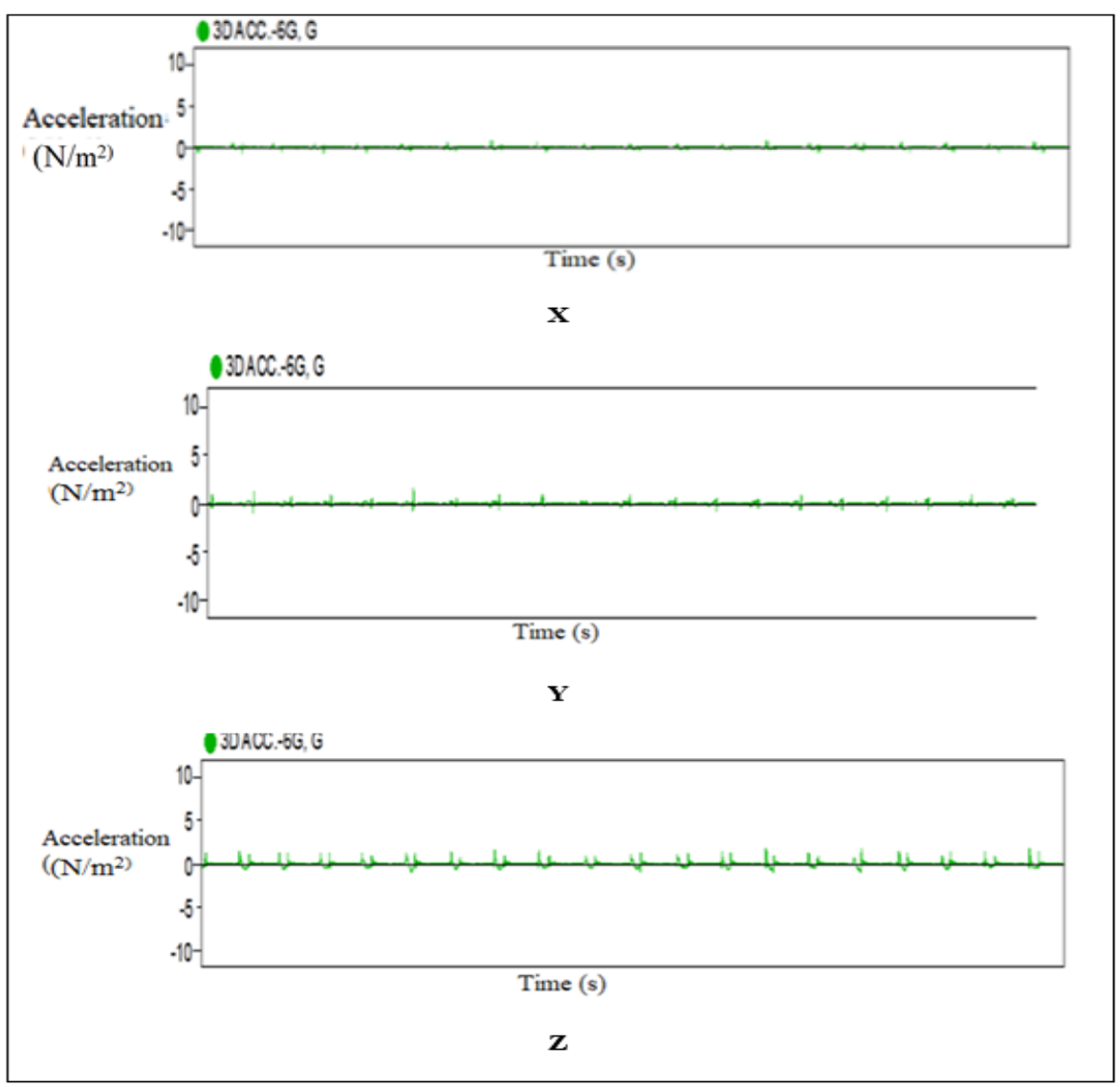

Figure 9: The acceleration - time curves in $x-y-z$ direction for foot for without damping

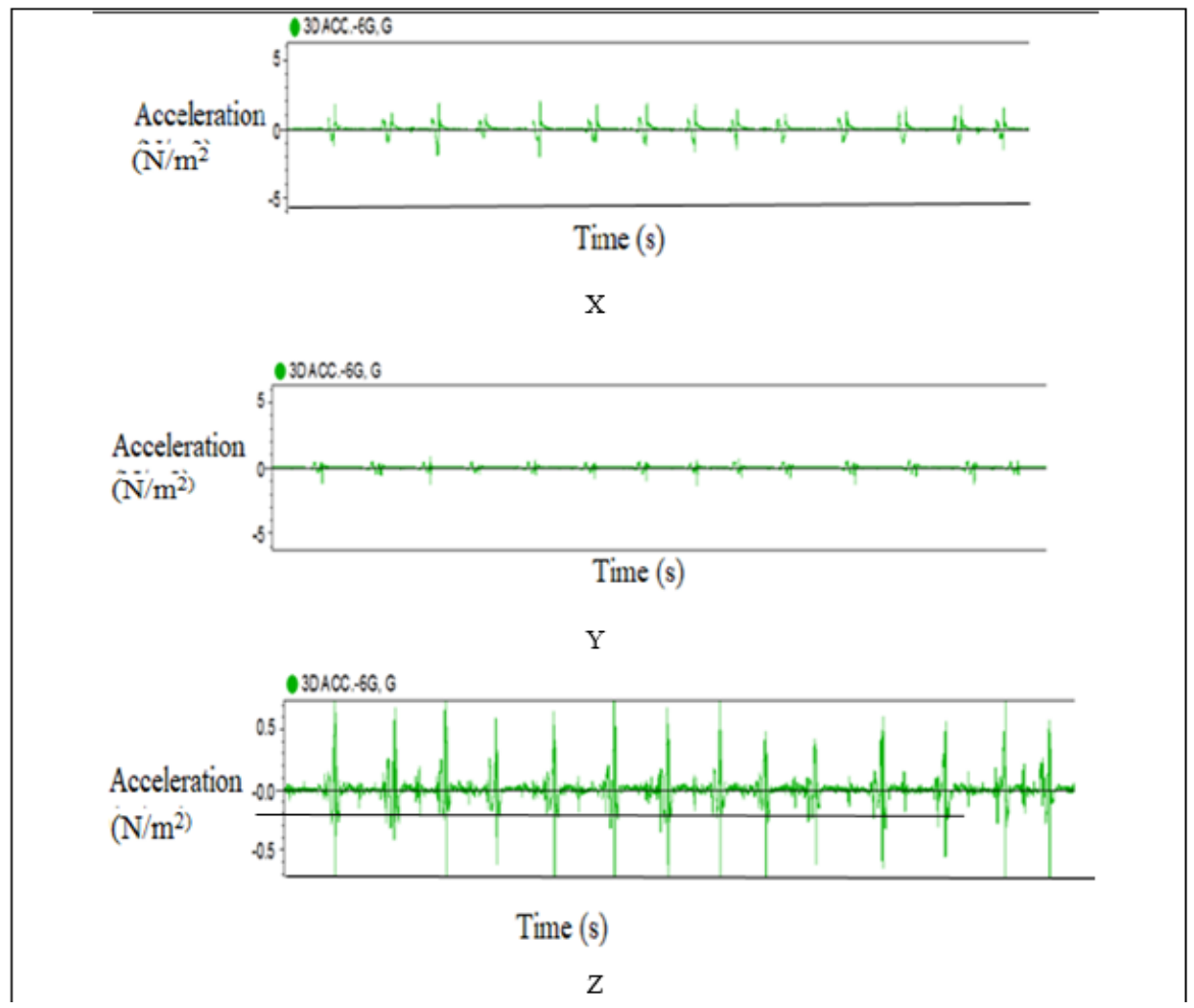

Figure 10: the acceleration-time curves in $x-y-z$ direction for foot for sport shoes with ground air 


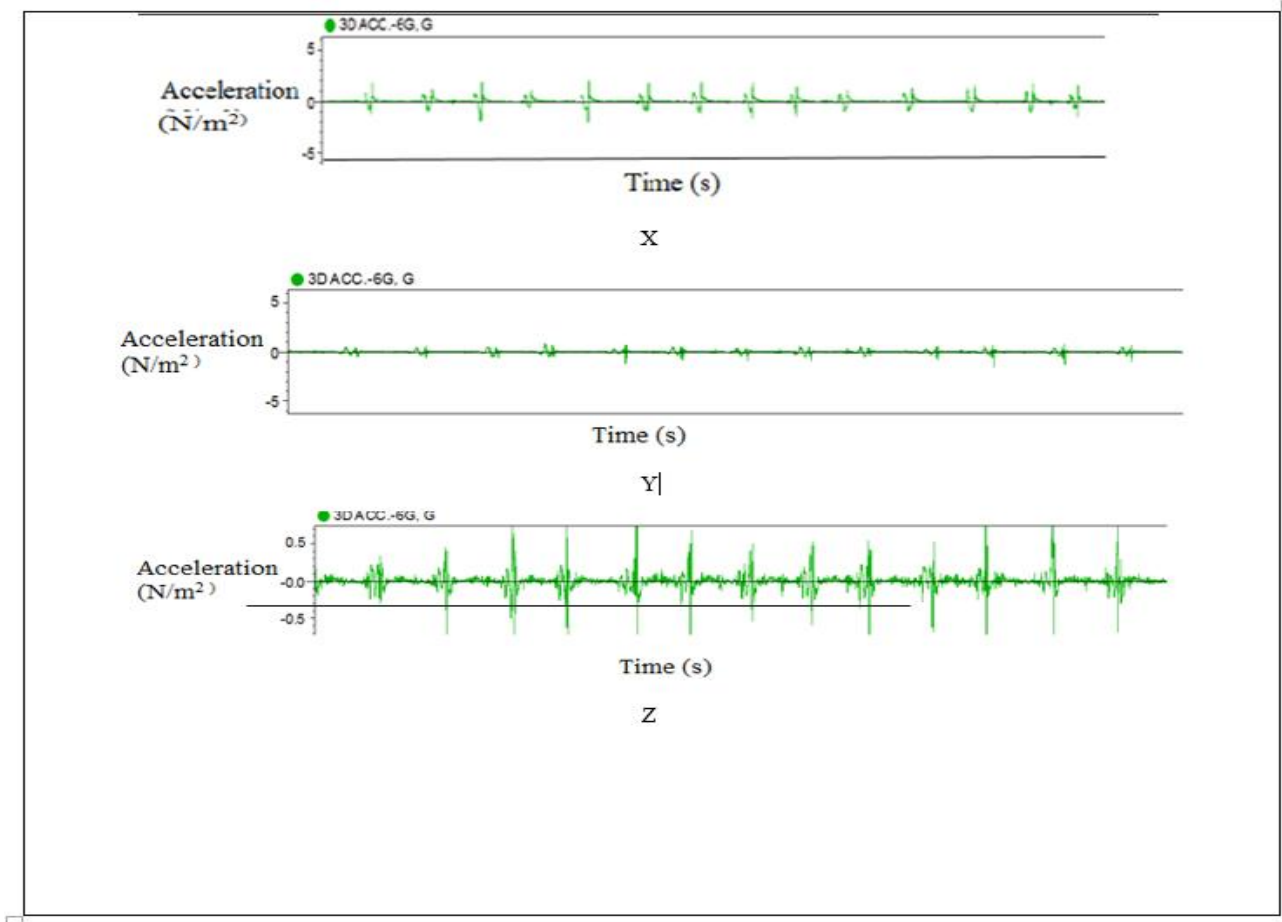

Figure 11: the acceleration-time curves in $x-y-z$ direction for foot for sport shoes with ground air with silicon damping.

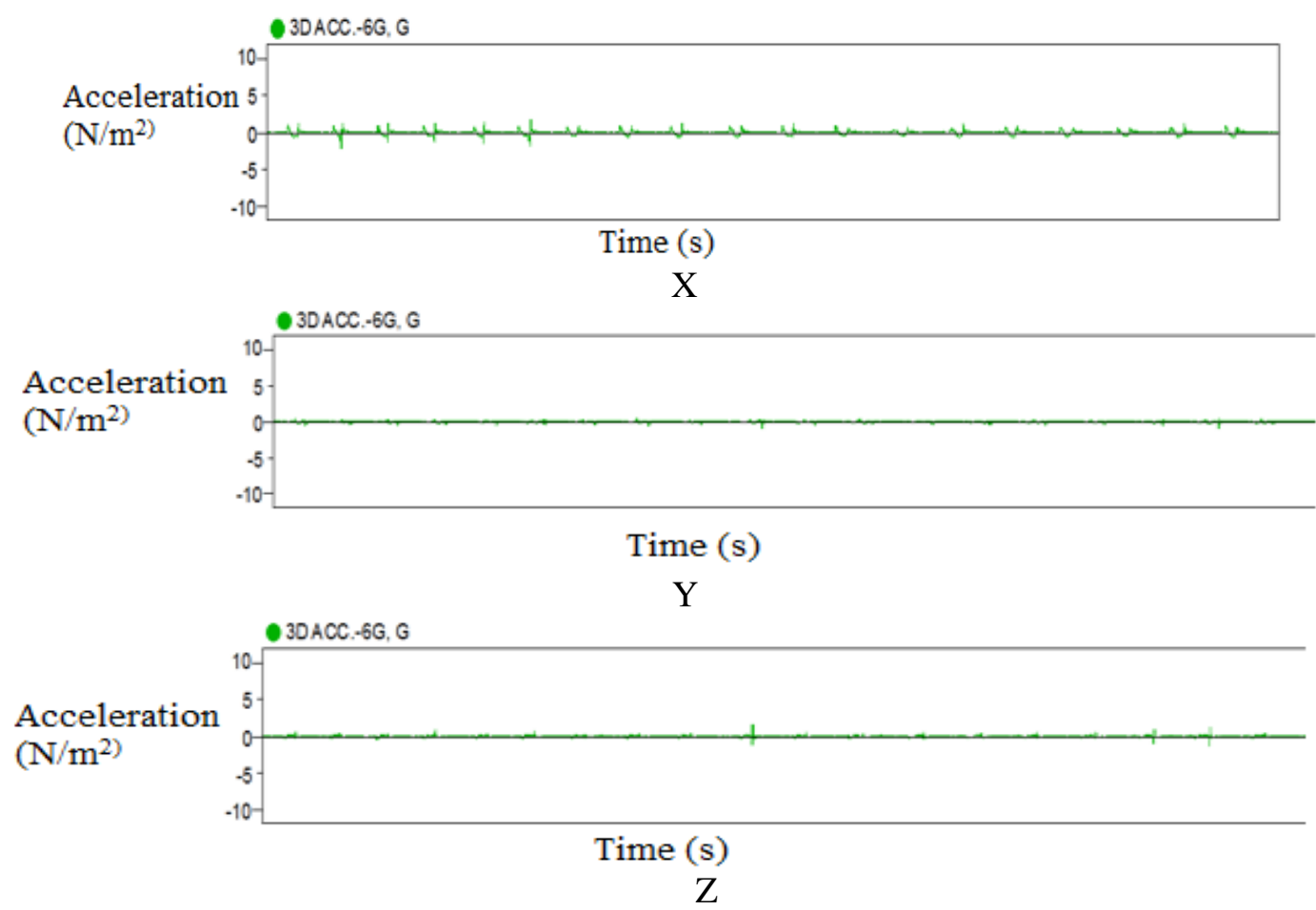

Figure 12: the acceleration-time curves in $x-y-z$ direction for knee without damping 


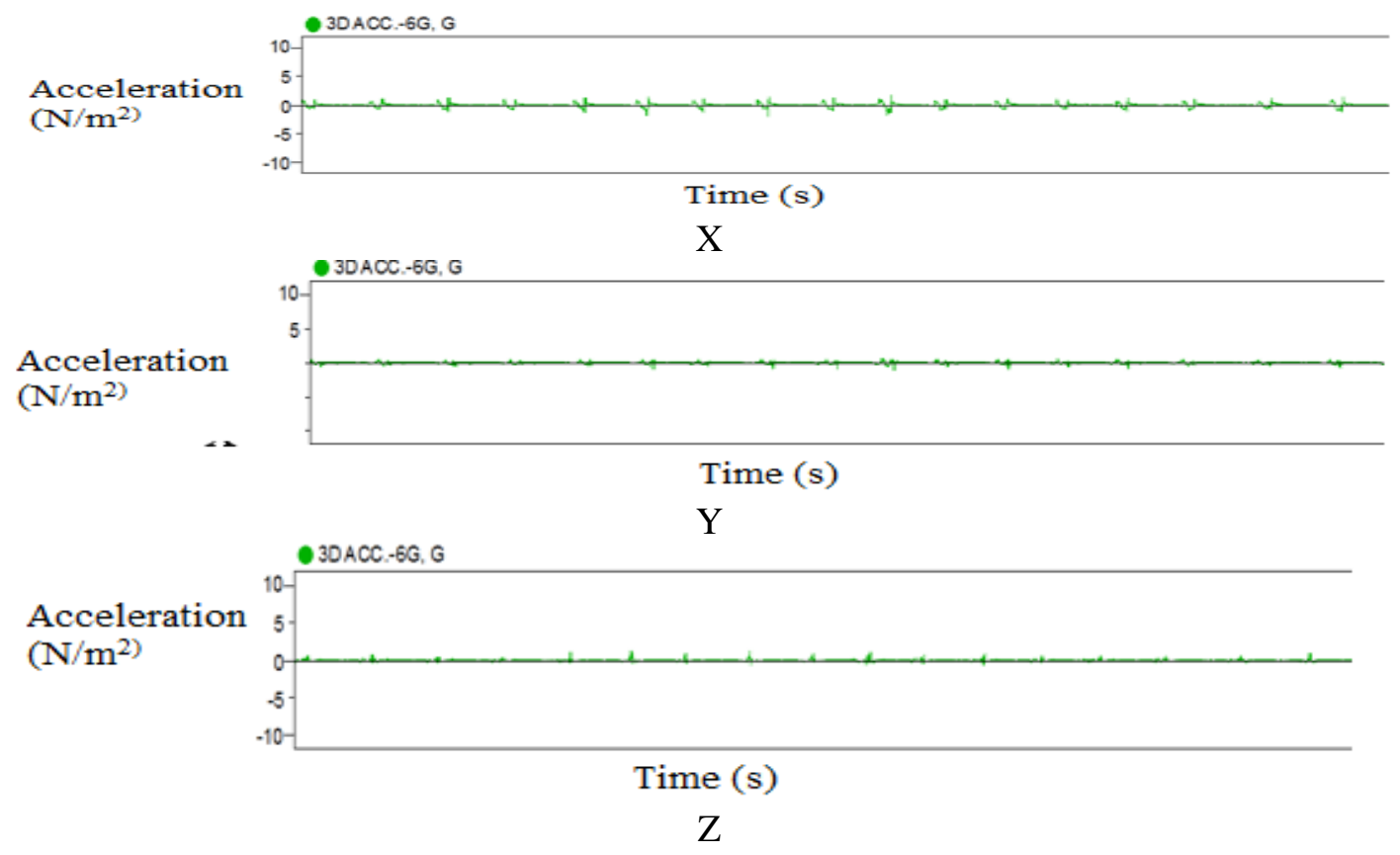

Figure 13: the acceleration-time curves in $x-y-z$ direction for knee for sport shoe with ground air

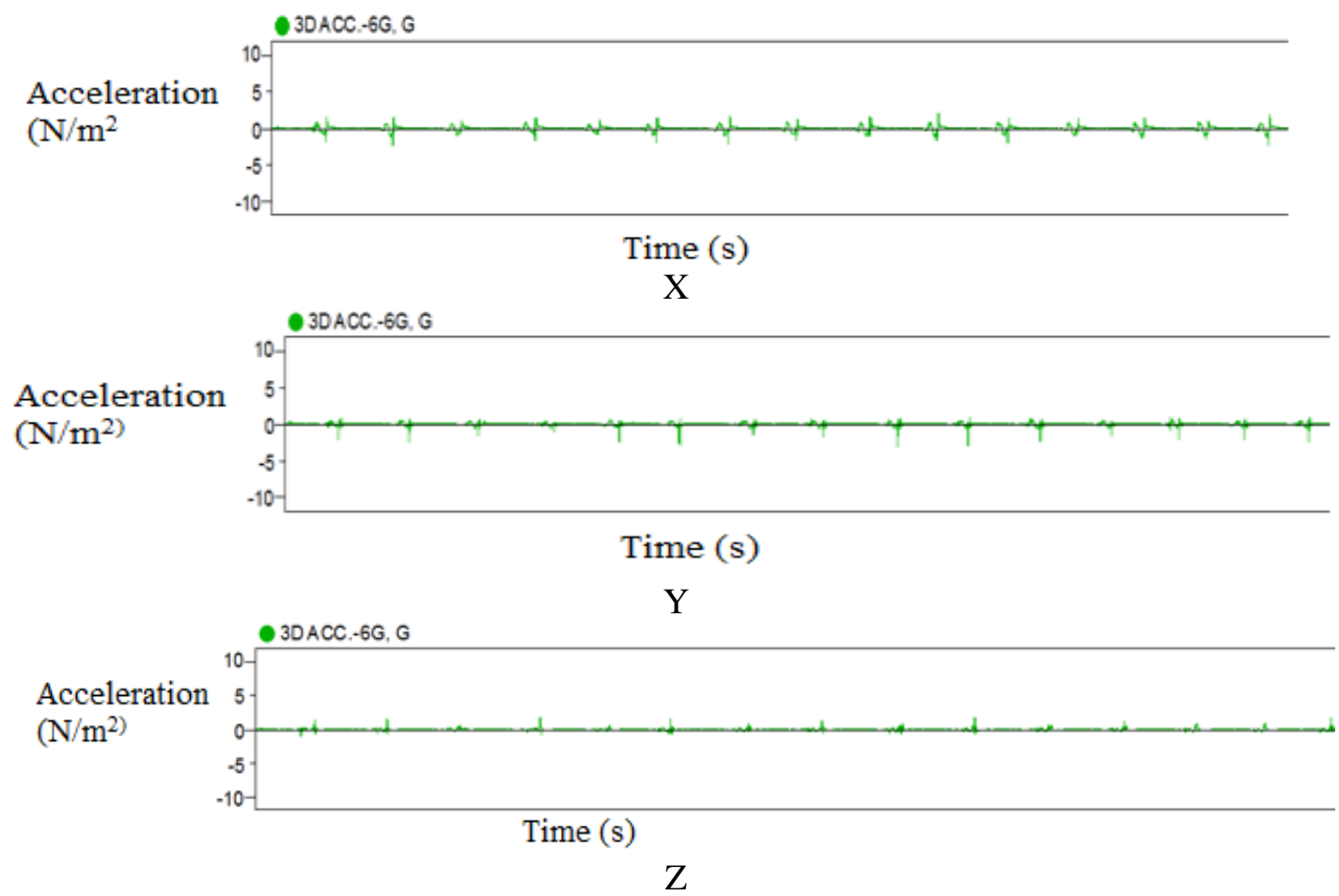

Figure 14: the acceleration-time curves in $x-y-z$ direction for knee for sport shoes with ground air with silicon damping.

Table 1: The acceleration values of the patient.

\begin{tabular}{|c|c|c|c|c|c|c|}
\hline Type of damping & \multicolumn{3}{|c|}{ Foot acceleration $\left({\mathrm{N} \backslash \mathrm{m}^{2}}^{2}\right)$} & \multicolumn{4}{|c|}{ Knee acceleration $\left(\mathrm{N}^{2}\right)$} \\
\hline & $\mathbf{X}$ & $\mathbf{Y}$ & $\mathbf{Z}$ & $\mathbf{X}$ & $\mathbf{Y}$ & $\mathrm{Z}$ \\
\hline Without damping (bare foot) & 0.41 & 0.49 & 0.3 & 0.31 & 0.19 & 0.17 \\
\hline Athletic shoes with ground air & 0.59 & 0.5 & 0.35 & 0.31 & 0.19 & 0.16 \\
\hline $\begin{array}{c}\text { Athletic shoes with ground air } \\
\text { with silicon damping }\end{array}$ & 0.46 & 0.42 & 0.21 & 0.29 & 0.17 & 0.15 \\
\hline
\end{tabular}


Table 2: Reduction percentage acceleration compared with without damping case

\begin{tabular}{|c|c|c|c|c|c|c|c|}
\hline \multirow{2}{*}{ Type of damping } & \multicolumn{3}{|c|}{ Foot acceleration \% } & \multicolumn{3}{|c|}{ Knee acceleration \% } & Reduction \\
\cline { 2 - 8 } & $\mathbf{X}$ & $\mathbf{Y}$ & $\mathbf{Z}$ & $\mathbf{X}$ & $\mathbf{Y}$ & $\mathbf{Z}$ & percentage \% \\
\hline Without damping (bare foot) & 0 & 0 & 0 & 0 & 0 & 0 & 0 \\
\hline $\begin{array}{c}\text { Athletic shoes with ground } \\
\text { air }\end{array}$ & -12.1 & 14.2 & 30 & 6.45 & 10.5 & 11.7 & 20.22 \\
\hline $\begin{array}{c}\text { Athletic shoes with ground } \\
\text { air with silicon damping }\end{array}$ & 7.3 & -18.3 & 53.3 & 9.67 & 15.78 & 0 & 22.57 \\
\hline
\end{tabular}

Figures 15 to 20 explain the frequency data for foot and knee joints respectively when using different type of damping foot. These results are rearranging in table 3.and table 4. which show that the level of frequency at knee joint is higher than foot .Results clarity that the maximum reduction in frequency was recorded when using Athletic shoes +ground air with percent of $-54.9 \%$.

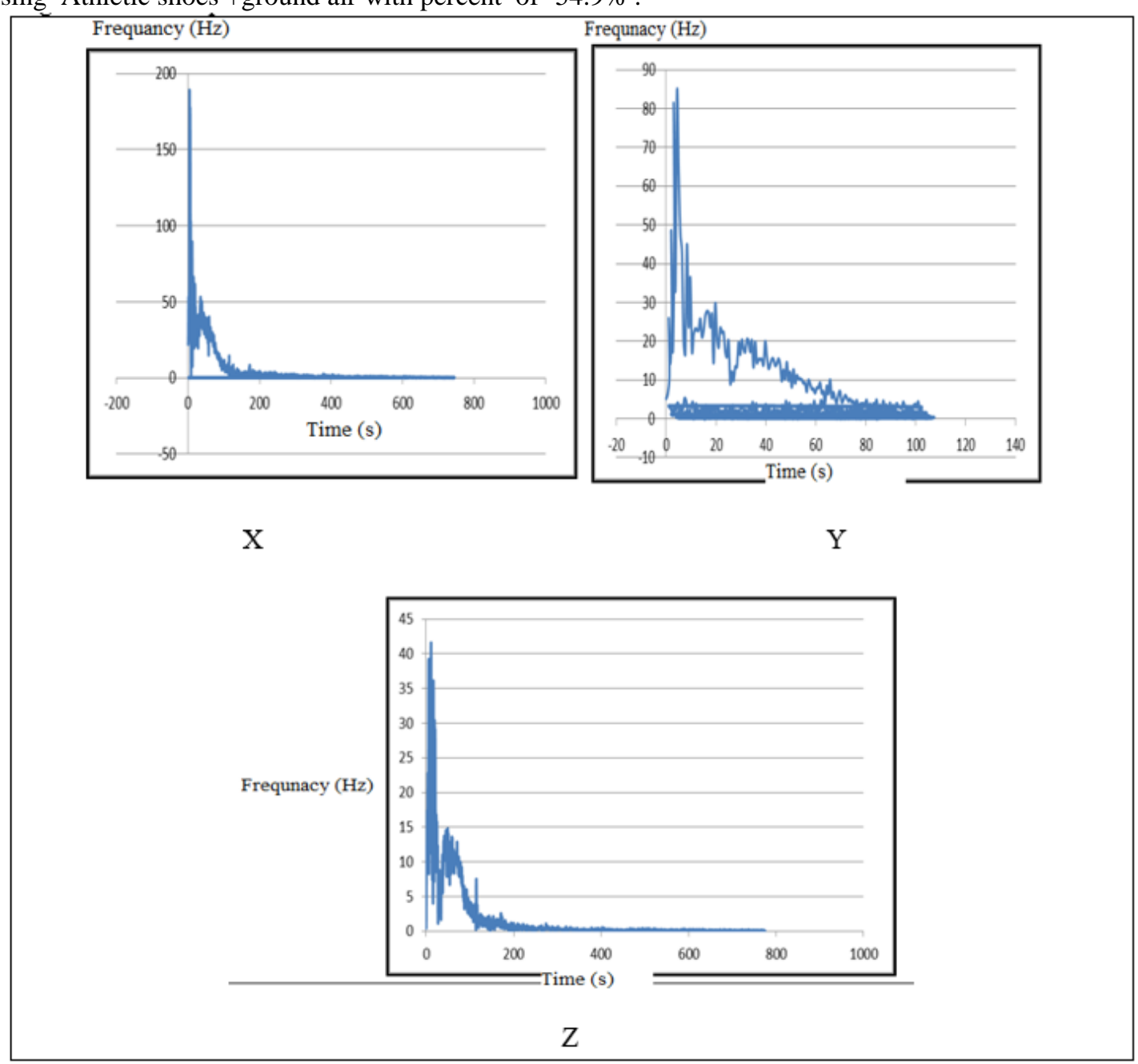

Figure 15: the frequency -time curves in $x-y-z$ direction for foot for without damping

\section{Conclusions}

1. The maximum reduction in acceleration be achieved when using sport shoes with ground air with silicon as a damping shoe with value of reduction of $22 \%$.
2. The maximum reduction in frequency be achieved when using sport shoes with ground air with value of reduction of $-54.9 \%$. 
3. The sport shoe with ground air with silicon damping was the best choice for the patient with total knee replacement.

\section{References}

[1] Baran, G.R., M.F. Kiani, and S.P. Samuel,"Biomaterials Applications in Medicine and Case Studies" in Healthcare and Biomedical Technology in the 21st Century. Springer. p. 249-285, 2014.

[2] George Bernard Shaw,"Gait and postural control after total knee arthroplasty", ISBN: 9-789-1760-1094-5, 2014.

[3] Kevin R. Math, Syed Furqan Zaidi, Catherine Petchprapa and Steven F. Harwin, "Imaging of Total Knee Arthroplasty" Seminars In
Musculoskeletal Radiology/Volume 10, Number 1 2006.

[4] Winter DA, "Kinematic and kinetic patterns in human gait: Variability and compensating effects". Hum Mov Sci 3:51-76. doi: 10.1016/01679457(84)90005-8, 1984.

[5] Fishwick J," Gait - A simple breakdown". http://plexuspandr.co.uk/uncategorized/gait-a, Simple-break down/, 2013.

[6] Saif Nalband, R. R. Sreekrishna and A. Amalin Prince," Analysis of Knee Joint Vibration Signals using Ensemble Empirical Mode Decomposition" Twelfth International Multi-Conference on Information Processing, Procedia Computer Science $89820-827,2016$.

\section{الحد من آثار معلمة الاهتزاز على مفصل الركبة البديلة أثناء دورة المشي اليومية

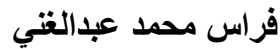 \\ كلية الطب \\ جامعة النهرين
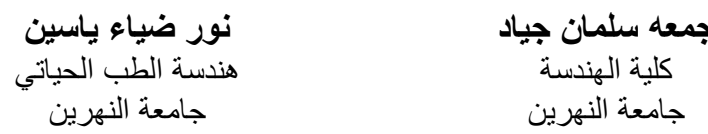 \\ جامعة النهرين النغين}

الخلاصه

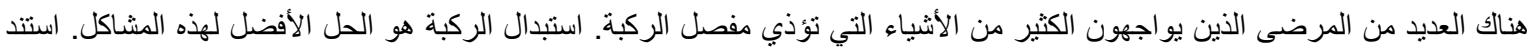

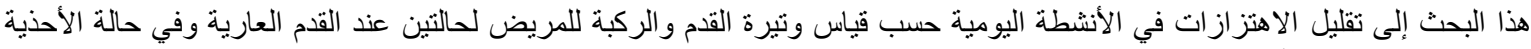

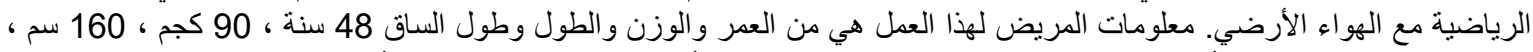

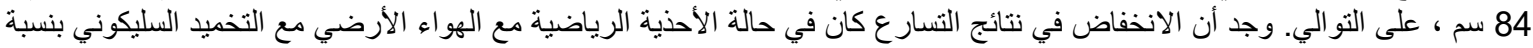

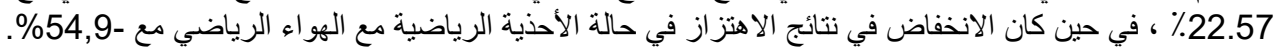

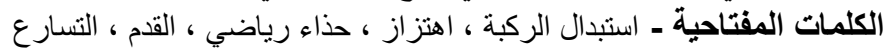

